\title{
WAVE LENGTHS OF THE STRONGER LINES IN THE HELIUM SPECTRUM
}

By Paul W. Merrill, Assistant Physicist

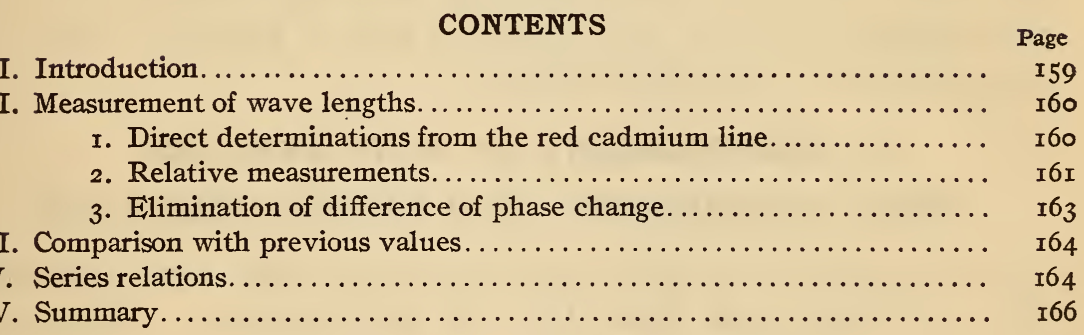

\section{INTRODUCTION}

For both practical and theoretical reasons the spectrum of helium is of considerable importance in spectroscopy and related branches of science. It consists of a comparatively small number of lines well distributed from the ultra-violet to the red, and is conveniently produced in great intensity in an ordinary vacuum tube. Hence it is widely used as a reference spectrum in spectroscopic and optical work of many kinds, but the wave lengths have not been known with sufficient accuracy for the most precise wave-length measurements. It is thought that the present determinations will supply this deficiency and make possible the use of helium lines as standards of wave length. This investigation is a part of the standard wave-length program of the Bureau of Standards, which has been under way for two years and which is at present chicfly concerned with the spectra of iron, argon, and neon. 
Helium is of great interest in astronomical observations as it is one of the most important elements from a cosmic viewpoint, its spectral lines being prominently observed in such radically different objects as nebulæ, early-that is, blue or white-stars and the sun (flash spectrum).

As an aid to progress in the comprehension of the structure of matter nothing is of greater promise than an accumulation of accurate data in regard to spectral-line series. Thanks to the early investigations of Runge and Paschen, every line observed in the ordinary spectrum of helium may be placed in one of six series. In order to establish the mathematical form of these series and to throw light on their relations to one another as well as to the series of other elements, exact values of the wave lengths of numerous lines will be required and will grow increasingly valuable as more data become available.

Precise measurements of the stronger helium lines were therefore undertaken in order that they may serve as standards for the determination of other wave lengths, and to furnish a basis for computations of theoretical interest.

\section{MEASUREMENT OF WAVE LENGTHS}

\section{DIRECT DETERMINATIONS FROM THE RED CADMIOM LINE}

Wave lengths of $2 \mathrm{I}$ of the stronger helium lines were measured with the Fabry and Perot type of interferometer, which consisted of two partially reflecting plane surfaces held a few millimeters apart and exactly parallel by an invar separator, using the practice previously adopted by the Bureau. ${ }^{1}$ The interference rings formed by the action of the parallel planes of the interferometer upon the incident light were projected upon the wide slit of a spectrograph having a single prism of rock salt, portions of them accordingly being observed as short bars across the spectral lines. The specially designed achromatic lenses allowed a great range of wave lengths to be photographed with one exposure. Thus, $2945 \mathrm{~A}$ and $5875 \mathrm{~A}\left(\mathrm{D}_{3}\right)$ were obtained on one plate as were also $3888 \mathrm{~A}$ and $728 \mathrm{IA}$.

The helium tube employed is similar in every way to the neon tube described by Meggers. ${ }^{2}$ It was filled at the Bureau with helium obtained from a London firm. The electrical excitation was furnished by stepping up from commercial alternating cur-

1 This Bulletin, 12, p. 179, 1915; 13, p. 245, 1916 (Scientific Papers Nos. 251 and 274).

This Bulletin, 12, p. 202 (Scientific Paper No. 25 I); 1913. 
rent of I Io volts, 60 cycles, to about 10000 volts (on open circuit). Primary currents from 0.5 to $\mathrm{I} .75$ a were used, causing from 3 to I I ma through the tube. The dark space was from I to 2 $\mathrm{mm}$ in width.

Several of the helium wave lengths were compared directly with the fundamental standard by photographing the cadmium and helium spectra simultaneously upon the same plate. The cadmium lamp, electrically heated to about $300^{\circ} \mathrm{C}$, was in the optical axis of the spectrograph, while the beam of helium light was brought into the axis by reflection from a partially transparent surface through which the cadmium light passed. This surface was formed by a thin film of nickel which had been cathodically deposited upon a quartz disk. Two series of photographs were made in this way, in one case the interferometer films being of copper deposited on glass and in the other of nickel on quartz. The copper interferometers employed were of 5 , Io, and $20 \mathrm{~mm}$ separation, the nickel of 5 , IO, I 5 , and $20 \mathrm{~mm}$. The plates (Seed 27) were sensitized to the less refrangible rays by treating them with a solution containing dicyanin, pinaverdol, and ammonia. Exposures were made ranging from 4 to 15 minutes and with varying amounts of current through the tube. The results are tabulated in Table I. The agreement of the two series is considered satisfactory except in the case of 7065A. No other reason, however, than accidental error of observation can be assigned for this difference.

The very small corrections to reduce the wave lengths to standard conditions $\left(760 \mathrm{~mm}, 15^{\circ} \mathrm{C}\right)$ were applied.

TABLE 1

Helium Wave Lengths by Direct Comparison With Cd 6438.4696

\begin{tabular}{|c|c|c|c|c|c|}
\hline Copper films & Nickel films & Adopted & Copper films & Nickel films & Adopted \\
\hline 3888.646 & 0.646 & 0.646 & $(5047.734)$ & & \\
\hline$\ldots \ldots$ & (4026. 190) & 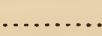 & 5875.616 & 0.618 & 0.617 \\
\hline 4471.476 & .478 & .477 & 6678.148 & .149 & .149 \\
\hline 4713.143 & .143 & .143 & 7065.186 & .190 & .188 \\
\hline 4921.928 & .929 & .929 & .7281 .350 & .348 & .349 \\
\hline 5015.675 & .675 & .675 & & & \\
\hline
\end{tabular}

\section{RELATIVE MEASUREMENTS}

The values in Table I served for the determination of other helium lines on photographs of the helium spectrum alone. In this series the nickel films and separations of $3,5,7.5$, and I $5 \mathrm{~mm}$ 
were used with exposures from 20 seconds to I hour. With the exception of the three red lines which were not observed in this series, the ratios of wave lengths in Table I were satisfactorily confirmed, and are apparently accurate to I part in 4000000 . The combined results of all the measurements made in this investigation appear in the first column of Table 2.

TABLE 2

Collected Helium Wave Lengths

\begin{tabular}{|c|c|c|c|c|}
\hline \multirow{2}{*}{$\begin{array}{l}\text { 'Bureau of } \\
\text { Standards }\end{array}$} & \multicolumn{2}{|c|}{ Rayleigh } & \multirow{2}{*}{$\begin{array}{l}\text { Evers- } \\
\text { heim }\end{array}$} & \multirow{2}{*}{$\begin{array}{l}\text { Runge } \\
\text { and } \\
\text { Paschen }\end{array}$} \\
\hline & (a) & (b) & & \\
\hline 2945.104 & & & & 106 \\
\hline 3187.743 & & & & 701 \\
\hline 3613.641 & & & & 641 \\
\hline 3705.003 & & & & 007 \\
\hline 3819.606 & & & & 605 \\
\hline 3838.616 & & & & 633 \\
\hline 3964.727 & & & & 727 \\
\hline 4026.189 & & & & 192 \\
\hline 4120.812 & & & & 821 \\
\hline 4143.759 & & & & 766 \\
\hline 4387.928 & & & & 934 \\
\hline 4137.549 & ..... & ...... & $\cdots$ & 549 \\
\hline 4471.477 & (478) & 480 & 493 & 475 \\
\hline 4713.143 & (171) & 142 & 154 & 074 \\
\hline 4921.929 & 925 & 928 & 922 & 919 \\
\hline 5015.675 & 680 & 678 & 683 & 556 \\
\hline 5047.736 & $\cdots$ & 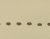 & & 641 \\
\hline 5875.618 & 616 & 623 & 639 & 650 \\
\hline 6678.149 & 144 & 147 & 151 & 14 \\
\hline 7065.188 & 189 & 197 & 207 & 22 \\
\hline 7281.349 & & & & 53 \\
\hline
\end{tabular}

From the number and internal agreement of the individual determinations it seems that an error larger than $0.003 \mathrm{~A}$ is scarcely to be expected and that probably most of the errors are smaller than that amount. In the case of the double lines the value, of course, refers to the stronger component. The weaker component seems to have been practically without effect upon the measurements, since accordant values were obtained from a considerable range both of effective exposures and of orders of interference.

This may be illustrated by the values obtained for $D_{3}$. It was customary to put several exposures of varying length upon each plate. Determinations of the difference between overexposed and normal or weak images are hence available for several plates. In 
units of a thousandth of an angstrom they run $\mathrm{o}, \mathrm{o},+\mathrm{I},+\mathrm{I},-3$, $+4,-5$, the last three depending on a poor measurement in each case. The systematic difference is not larger than the accidental error. The photographs of helium alone were taken upon Seed 27 emulsion (not stained), but the longest exposure on each plate (about an hour) shows $D_{3}$ faintly. The wave lengths of this line from four of these underexposed images are practically in agreement with the other determinations, there being possibly a tendency toward a slightly higher value. For 5 or $5 \mathrm{~A}$, a single line, the difference, strong minus weak exposure, is 0.000 or $\pm 0.001 \mathrm{~A}$ in

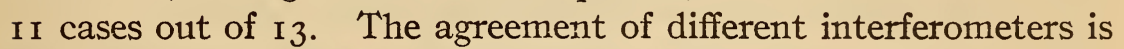
shown for two lines by Table 3 , which refers entirely to the direct comparisons with cadmium. The small figures in parentheses give the number of exposures upon which the value depends.

TABLE 3

\section{Wave Lengths from Different Interferometers}

[Comparisons with cadmium]

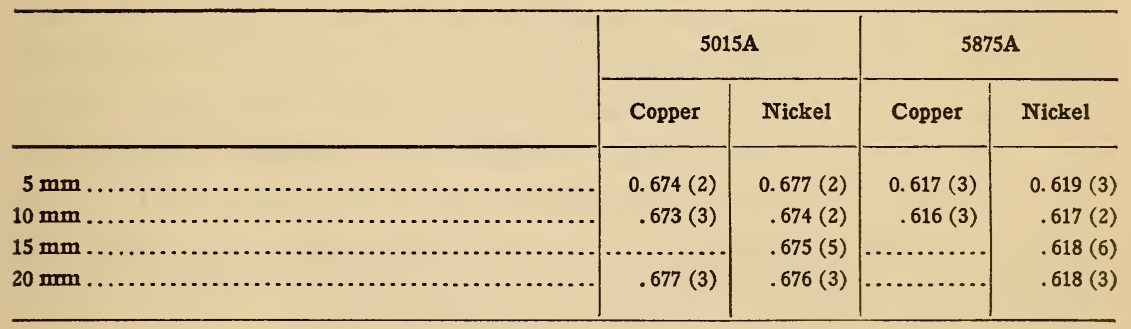

\section{ELIMINATION OF DIFFERENCE OF PHASE CHANGE}

The dispersion of phase change at reflection from the interferometer mirrors has been referred to as "one of the less agreeable features" of interference measurements. It is customary to find the amount of the differential effect for different wave lengths by observations with large and small path differences, and to compute the small corrections to be applied to the measured wave lengths. This procedure is, however, by no means necessary, as the whole effect can be eliminated by using differences, as was done by Priest ${ }^{3}$ for visual methods. Let us find by the use of the standard line, say Cd6438A, the double thickness of a large and of a small interferometer. If the difference of these numbers be divided by the difference of the measured orders of interference for another line, it is obvious that the quotient will be the 
correct wave length freed from any effect of difference of phase change without having found that quantity at all. The difference of the orders will be of about the same accuracy as the larger one, for while the percentage error of the smaller may be greater the actual numerical uncertainty is less.

The same final values should, of course, be arrived at whether the difference of phase change is eliminated as suggested above or determined by the usual methods and the proper corrections applied. This is the case in the present series of measurements.

\section{COMPARISON WITH PREVIOUS VALUES}

The present measurements and those by Lord Rayleigh " are in quite good agreement as shown by Table 2 . Columns 2 (a) and 2 (b) are separate series of which the second is to be given greater weight. Eversheim's values ${ }^{5}$ are greater, but the differences are not uniform. Except for $3187 \mathrm{~A}$ the grating values of the shorter wave lengths by Runge and Paschen ${ }^{6}$ are in good accord with the interference results. The discrepancies among the longer wave lengths are possibly due in some way to the fact that their measurements depend upon comparison lines in another order (second). This is the case for $47 \mathrm{I} 3,492 \mathrm{I}, 5015,5047,5875$, 5678 , and $7065 \mathrm{~A}$. The mean arithmetic residual Runge and Paschen minus Bureau of Standards for these lines is $0.052 \mathrm{~A}$, as compared with $0.0065 \mathrm{~A}$ for the remaining lines, for which the comparisons were in the first order. Omitting $3 \mathrm{IS} / \mathrm{A}$ the mean residual for $\mathrm{I} 2$ of the shorter lines is only $0.003 \mathrm{~A}$.

Using an interference method which depends upon observing the disappearance of the central ring ${ }^{7}$ Priest found the apparent wave lengths of certain helium lines to vary with the amount of current through the tube. Variations of this kind were not observed by him for $5015 \mathrm{~A} .{ }^{8}$ Mr. Priest has kindly given me the exact value obtained by him for this line as 5015.679A. This is the mean of several accordant measurements.

\section{SERIES RELATIONS}

When our understanding of spectral series is complete, the magnitudes of certain physical quantities can probably be computed from a single series, and from relations between different series, and it may be in this connection that accurate measurements of wave length will finally be of the most value. In the

Phil. Maz. (6), 15, p. 545; 1908.

'Zs. wiss Photo., S. p. 145; rgog.

-Astroph. Jour., 3. p. 4 ; 1 \$g6.
7 This Bulletin, 6, p. 573 (Reprint No. 142); 1911 .

- This Bulletin. S, p. I (Reprint No. 179); 1918. 
meantime they can be used to determine the applicability of the various types of formula which have been suggested, to test the so-called "combination principle," etc. For obvious reasons the present investigation includes only a small number of lines at or near the beginning of each series. These lines, although favorably situated for the purpose, will not by themselves give the best values of the series constants, particularly of the convergence frequency. Hence no extensive recomputations have been undertaken at this time, but it was thought of interest to see how closely a three-constant formula based upon three consecutive well-determined lines would represent the remainder of the series.

None of the series can be represented exactly by a formula of the type

$$
n=A-B / m^{2}
$$

where $n$ is the reciprocal of the wave length, $m$ represents successive integers, $A$ and $B$ are constants. This equation, however, gives a fairly close representation of the two first subordinate series (5875A, 447 r A, etc.; 6678 A, 492 IA, etc.). The constant $B$ is about the same for both and approximately 0.2 per cent larger than in the Balmer series of hydrogen.

It is well known that the Kayser and Runger formula

$$
n=A-B / m^{2}-C / m^{3}
$$

will give a fair representation of the helium series. The lines for which $m=3,4,5$, in each of the six series have been measured in the present investigation. The constants $A, B, C$, as computed from these three lines, appear in Table 4 , which also contains the residuals of all the well-observed lines in each series.

In every instance the error of the representation even for $m=6$ is very much larger than the uncertainty of observation, while the residuals show a fairly smooth and converging increase toward the terms of higher order. In some cases there is no improvement as compared with the series computed by Kayser and Runge from less accurate values. This is in agreement with the prevailing opinion that the formula contains the first three terms of a rapidly converging mathematical series which may be regarded as the expansion of a closed expression as yet unknown. 


\section{TABLE 4}

\section{Series Constants}

$$
n(\mathrm{vac})=A-\frac{B}{m^{2}}-\frac{C}{m^{3}}
$$

CONSTANTS COMPUTED FROM $m=3,4,5$, IN EACH SERIES

\begin{tabular}{|c|c|c|c|c|c|c|}
\hline & \multicolumn{3}{|c|}{ First group } & \multicolumn{3}{|c|}{ Second group } \\
\hline & Principal & $\begin{array}{c}\text { First sub- } \\
\text { ordinate }\end{array}$ & $\begin{array}{l}\text { Second } \\
\text { subordi- } \\
\text { nate }\end{array}$ & Principal & $\begin{array}{l}\text { First sub- } \\
\text { ordinate }\end{array}$ & $\begin{array}{l}\text { Second } \\
\text { subordi- } \\
\text { nate }\end{array}$ \\
\hline A. & 38469.22 & 29225.53 & 29147.13 & 32030.82 & 27176.66 & 27154.51 \\
\hline B.... & 110501.7 & 109845.2 & 102963.4 & 109518.3 & 109783.2 & 107878.3 \\
\hline c.......... & 13027.4 & 152.7 & 96030.4 & -1887.8 & 226.2 & 38826.8 \\
\hline
\end{tabular}

OBSERVED MUNUS COMPUTED (ANGSTROMS)

\begin{tabular}{|c|c|c|c|c|c|c|}
\hline $\mathbf{M}$ & & & & & & \\
\hline $2 \ldots$ & -18.2 & $\cdots$ & .. & +124.3 & 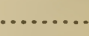 & \\
\hline 3... & 0 & 0 & 0 & 0 & 0 & 0 \\
\hline 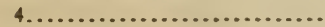 & 0 & 0 & 0 & 0 & 0 & 0 \\
\hline $5 \ldots \ldots \ldots \ldots$ & 0 & 0 & 0 & 0 & 0 & 0 \\
\hline $6 . \ldots \ldots .$. & +0.18 & +0.021 & -1.06 & -0.030 & +0.013 & -0.34 \\
\hline $7, \ldots \ldots \ldots \ldots \ldots \ldots \ldots \ldots \ldots$ & +.34 & +.047 & -2.2 & -.091 & +.036 & -0.71 \\
\hline $8 \ldots$. & +.45 & +.078 & -3.2 & -.103 & +.022 & -1.07 \\
\hline $9 \ldots \ldots \ldots \ldots \ldots \ldots \ldots$ & +.56 & +.096 & -4.0 & -.19 & +.068 & -1.30 \\
\hline $10 . .$. & & +.134 & & -.21 & +.069 & -1.54 \\
\hline $11 \ldots$ & & ..... & & -.23 & +.072 & ‥ \\
\hline ... & & & & & +.090 & \\
\hline
\end{tabular}

\section{SUMMARY}

Wave lengths of $2 \mathrm{I}$ of the stronger helium lines have been accurately measured by interference methods. Nine of them were compared directly with the standard cadmium line.

The possibility of eliminating the effect of apparent variation of interferometer thickness with wave length is noted.

The Kayser and Runge formula for spectral series, based upon three consecutive lines, will not reproduce accurately even the next member in any one of the six helium series.

WASHINGTON, March I4, I9I 7. 